\author{
理论研究 8-氮杂鸟嘌呤自由基阳离子脱质子反应 \\ 王英辉 ${ }^{\dagger}, a$ 魏思敏 ${ }^{\dagger}, *, b \quad$ 王康 $^{a} \quad$ 徐蓉蓉 $^{b} \quad$ 赵红梅 $^{*, c}$ \\ ( ${ }^{a}$ 长安大学理学院 西安 710064) \\ $\left({ }^{b}\right.$ 陕西中医药大学 陕西省中药资源产业化协同创新中心 咸阳 712083) \\ ( ${ }^{c}$ 中国科学院化学研究所 北京分子科学国家实验室 北京 100190)
}

\begin{abstract}
摘要 由于 8 -氮杂鸟嘌呤 $(8-A G)$ 的氧化还原电势比鸟嘌呤 $(G)$ 更低, 所以单电子氧化嵌有 8-AG 的 DNA后, 空穴最终会 被 8-AG 捕获形成 8-氮杂鸟嘌呤自由基阳离子 $\left(8-\mathrm{AG}^{\circ+}\right)$. 因为酸性的急剧增强, $8-\mathrm{AG}^{\circ+}$ 一般会发生脱质子反应. 在本工 作中，在 M06-2X/6-31+G(d)理论水平，使用显性水分子和连续溶剂化模型模拟 $8-\mathrm{AG}^{{ }^{+}}$的溶剂化效应，对其脱亚氨基质 子 $(\mathrm{N}(1)-\mathrm{H})$ 反应进行了研究. 发现位于 $8-\mathrm{AG}^{\cdot+}$ 中 $\mathrm{N}(1)-\mathrm{H} 、 \mathrm{O}(6) 、 \mathrm{~N}(2)-\mathrm{H}$ 附近以及在 $\mathrm{O}(6)$ 水分子附近稍微远离 $8-\mathrm{AG}^{\cdot+}$ 的 4 个水分子会对 $8-\mathrm{AG}^{\cdot+}$ 脱质子反应产生重要影响, 质子从 $8-\mathrm{AG}^{\cdot+}$ 传递到溶液中具有方向性; 最后, 通过进一 步在 $\mathrm{N}(2)-\mathrm{H} 、 \mathrm{~N}(3) 、 \mathrm{O}(6) 、 \mathrm{~N}(7)$ 和 $\mathrm{N}(8)$ 等位点附近添加水分子 $\left(9 \mathrm{H}_{2} \mathrm{O}\right)$ 得到了更加精确的 $8-\mathrm{AG}^{\cdot+}$ 脱质子反应能垒 $(19.5$ $\mathrm{kJ} / \mathrm{mol})$.
\end{abstract}

关键词 8-氮杂鸟嘌呤; 单电子氧化; 脱质子反应; 势能面

\title{
A Theoretical Study of 8-Azaguanine Radical Cation Deprotonation
}

\author{
Wang, Yinghui ${ }^{\dagger, a} \quad$ Wei, Simin ${ }^{\dagger}, *, b \quad$ Wang, Kang $^{a} \quad$ Xu, Rongrong ${ }^{b} \quad$ Zhao, Hongmei ${ }^{*}, c$ \\ $\left({ }^{a}\right.$ College of Science, Chang'an University, Xi'an 710064) \\ ( ${ }^{b}$ Shaanxi Collaborative Innovation Center of Chinese Medicine Resources Industrialization, \\ Shaanxi University of Chinese Medicine, Xianyang 712083) \\ ( ${ }^{c}$ Beijing National Laboratory for Molecular Science (BNLMS), Institute of Chemistry, Chinese Academy of Sciences, \\ Beijing 100190)
}

\begin{abstract}
Due to the lower redox potential comparing with guanine, it is the 8-azaguanine (8-AG) as the hole trap to form 8 -azaguanine radical cation $\left(8-\mathrm{AG}^{\cdot+}\right)$ after one-electron oxidation of DNA containing 8-azaguanine. In generally, the 8-AG ${ }^{\cdot+}$ may suffer from deprotonation to generate $8-\mathrm{AG}(-\mathrm{H})^{\circ}$. In this text, we were stimulated to investigate the deprotonation reaction of $8-\mathrm{AG}^{\cdot+}$ generating by one-electron oxidation at $\mathrm{M} 06-2 \mathrm{X} / 6-31+\mathrm{G}(\mathrm{d})$ level with explicit water molecules and polarized continuum model (PCM) to simulate the solvent effect. By building deprotonation model with different number of explicit water molecules, we found that these four water molecules locating around $\mathrm{N}(1)-\mathrm{H}, \mathrm{O}(6), \mathrm{N}(2)-\mathrm{H}$ of $8-\mathrm{AG}^{{ }^{+}}$as well as the one locating in the second water shell which was hydrogen-bonding with the water around $\mathrm{O}(6)$ were necessary. If the water in the second water shell was not included, the imino proton $(\mathrm{N}(1)-\mathrm{H})$ would not transfer into the bulk water. In parallel, the $\mathrm{N}(1)-\mathrm{H}$ would transfer to the $\mathrm{O}(6)$ of $8-\mathrm{AG}^{\cdot+}$ by intramolecular proton transfer. If the water molecule locating around $\mathrm{N}(2)-\mathrm{H}$ was removed, the $8-\mathrm{AG}^{{ }^{+}}$deprotonation would continue but the energy barrier would be lowered from 24.8 $\mathrm{kJ} / \mathrm{mol}$ to $16.3 \mathrm{~kJ} / \mathrm{mol}$. In addition, the site of the water molecule in the second water shell was also studied. If putting the water in the second water shell around $\mathrm{N}(2)-\mathrm{H}$ of $8-\mathrm{AG}^{\cdot+}$, the proton would be stabilized between the $\mathrm{N}(1)$ of $8-\mathrm{AG}^{\cdot+}$ and the oxygen of water molecule around $\mathrm{N}(1)-\mathrm{H}$ meaning the proton would not be transferred into bulk water. Further, in order to test the influence of water number on $8-\mathrm{AG}^{\cdot+}$ deprotonation, the fifth water molecule, which is hydrogen-bonding with the water molecule around $\mathrm{N}(2)-\mathrm{H}$ and another $\mathrm{N}(2)-\mathrm{H}$, was added. The potential energy surface with $5 \mathrm{H}_{2} \mathrm{O}$ revealed that it is almost no effect on the deprotonation pathway and energy barrier $(25.5 \mathrm{~kJ} / \mathrm{mol})$. Lastly, so as to obtain the exact energy barrier of $8-\mathrm{AG}^{*+}$ deprotonation, the deprotonation model with more explicit water molecules $\left(9 \mathrm{H}_{2} \mathrm{O}\right)$ was proposed, where the additional water molecules were placed around $\mathrm{N}(2)-\mathrm{H}, \mathrm{N}(3), \mathrm{O}(6), \mathrm{N}(7)$ and $\mathrm{N}(8)$. From the potential energy surface, the deprotonation energy barrier of $8-\mathrm{AG}^{*+}$ was confirmed to be $19.5 \mathrm{~kJ} / \mathrm{mol}$. These theoretical results provide valuable dynamics information and mechanistic insights for further understanding the properties of nucleic acid base analogues and one-electron oxidation of DNA.
\end{abstract}

Keywords 8-azaguanine; one-electron oxidation; deprotonation reaction; potential energy surface

\footnotetext{
*E-mail: weisimin@iccas.ac.cn; hmzhao@iccas.ac.cn

$\uparrow$ These authors contributed equally to this work.

Received December 18, 2019; published February 9, 2020.

Supporting information for this article is available free of charge via the Internet at http://sioc-journal.cn.

Project supported by the National Natural Science Foundation of China (No. 21705029) and the Shaanxi Provincial Association for Science and Technology Young Talents Lifting Plan (No. 20190307).

项目受国家自然科学基金(No. 21705029)和陕西省高校科协青年人才托举计划(No. 20190307)资助.
} 


\section{1 引言}

核酸碱基类似物是一类重要的分子，它们与正常的 核酸碱基结构类似, 但是在光化学与光物理以及生物化 学活性(致癌和抗肿瘤效应)等方面却有很大的差别 ${ }^{[1 \sim 4]}$. 8-氮杂鸟嘌呤 (8-Azaguanine, 简称 8-AG)是一种重要的 DNA 碱基类似物, 当将鸟嘌呤碱基 8 号位上的碳原子用 氮原子取代后形成, 结构如图 1 所示. 在生物学层面, 8-AG 可以通过嵌入肿瘤细胞信使核糖核酸(mRNA)片 段, 抑制肿瘤细胞蛋白质的合成 ${ }^{[5,6]}$. 在临床上, 8-AG 已 被成功应用于治疗急性白血病、子宫癌和乳腺癌等. 此 外, 有报道显示: 在缺氧条件下, 只要有微摩尔量级一 氧化氮(NO, 辐射增敏剂)的存在, $\gamma$-辐射 $2^{\prime}$-脱氧鸟苷单 磷酸盐(dGMP) 就会有 $2^{\prime}$-脱氧-8-氮鸟苷单磷酸盐生成 (8-azadGMP); 进一步的 $\gamma$-辐射质粒 DNA 后也会检测到 8-azadGMP 生成, 基于此他们推测: 在缺氧条件下, NO 引发的辐射增敏效应可能源于 8-azadGMP 等碱基类似 物的生成 ${ }^{[7]}$. 因此, 8-AG 已受到各国科研工作者的广泛 关注. 但是目前对于氮杂嘌啉碱基的研究主要集中在其 光物理性质的研究, 对于光化学反应的研究很少 ${ }^{[8 \sim 10]}$.

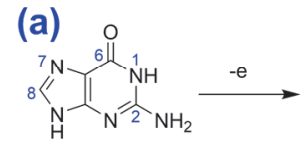

G

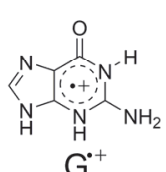

$\mathrm{G}^{+}$
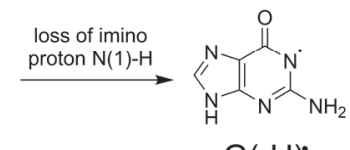

$\mathrm{G}(-\mathrm{H})^{\circ}$

(b)<smiles></smiles>

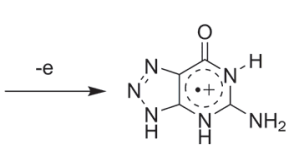

$8-\mathrm{AG}^{\cdot+}$

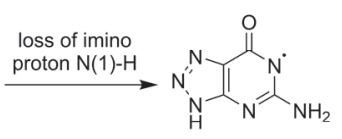

$8-A G(-H)^{\circ}$
图 1 单电子氧化(a) $\mathrm{G}$; (b) 8- $\mathrm{AG}$ 后 $\mathrm{G}^{-+}$和 $8-\mathrm{AG}^{-+}$脱质子反应

Figure 1 The deprotonation pathway of (a) $\mathrm{G}^{\cdot+}$ and (b) $8-\mathrm{AG}^{\cdot+}$ after one-electron oxidation of $\mathrm{G}$ and 8-AG

当将 DNA 分子暴露于电离辐射、光敏剂或者单电 子氧化试剂如 $\mathrm{SO}_{4}{ }^{-}$等时, DNA 分子会失去一个电子形 成 DNA 自由基阳离子(空穴), 形成的空穴会沿着 DNA 链传递 ${ }^{[11 ~ 16]}$. 因为在四个 DNA 碱基分子中, $\mathrm{G}$ 碱基的氧 化还原电势最低 $(\mathrm{G}<\mathrm{A}<\mathrm{C}<\mathrm{T})$, 所以初始产生的 DNA 自由基阳离子最终会被 $\mathrm{G}$ 碱基捕获形成鸟嘌呤自由基 阳离子 $\left(\mathrm{G}^{\cdot+}\right)^{[17,18]}$. 因为电子的损失使得 $\mathrm{G}$ 碱基中活性质 子的酸性急剧增强, 所以 $\mathrm{G}^{+}+$会首先发生脱质子反应形 成 $\mathrm{G}(-\mathrm{H})$ 并进一步通过与 $\mathrm{O}_{2}$ 等反应生成咪唑啉酮 (imidazolone, 简称 $\mathrm{Iz}$ )、噁唑酮(oxazolone, 简称 $\mathrm{Oz}$ ) 等 损伤产物, 或者当脱质子反应被轻微抑制时 $(\mathrm{pH}<3.9$ 或 者处于 DNA 链中), $\mathrm{G}^{-+}$也可与水分子反应生成 7,8-二氢 -8-氧鸟嘌呤 $(7,8$-dihydro-8-oxoguanine, 简称 8-oxoG)等 损伤产物, 从而造成 DNA 单电子氧化损伤 ${ }^{[19-22]}$. 如果 这些损伤不被移除, 最终可能加速细胞的衰老、死亡甚 至导致癌症等疾病 ${ }^{[23]}$. 因此了解单电子氧化 DNA 后形
成的自由基阳离子的反应已被广泛关注. 根据文献 ${ }^{[24]}$ 报道，当 $\mathrm{G}$ 碱基的 8 号位 $\mathrm{C}$ 被 $\mathrm{N}$ 取代形成 8-AG 后其氧 化还原电势会降低, 所以单电子氧化包含有 $8-\mathrm{AG}$ 的 DNA 后, 空穴最终会被 8-AG 捕获形成 8-AG 自由基阳 离子 $\left(8-\mathrm{AG}^{\circ+}\right)$. 因此研究 $8-\mathrm{AG}$ 被单电子氧化后的反应 本身就具有其生物学意义.

在本工作中，我们通过密度泛函 M06-2X，在 6-31 $+\mathrm{G}(\mathrm{d})$ 理论水平上, 使用显性水分子与连续极化介质模 型 $(\mathrm{PCM})$ 模拟 $8-\mathrm{AG}^{\circ+}$ 的微环境, 构建了 $8-\mathrm{AG}^{-+}$脱质子反 应模型—- $4 \mathrm{H}_{2} \mathrm{O}-\mathrm{PCM}$ 模型，并在 $4 \mathrm{H}_{2} \mathrm{O}-\mathrm{PCM}$ 模型的基 础上对不同位置的水分子在 $8-\mathrm{AG}^{\circ+}$ 脱质子过程中的作 用进行了研究. 我们发现: 在溶剂水分子帮助下的 $8-\mathrm{AG}^{*+}$ 脱质子反应中, 脱质子位点 $\mathrm{N}(1)-\mathrm{H}_{\mathrm{a}}$ 附近须有 4 个水分子, 其中 3 个水分子与 $8-\mathrm{AG}^{\circ}{ }^{+}$直接通过氢键发生 作用, 分别位于 $8-\mathrm{AG}^{-+}$中的 $\mathrm{N}(1)-\mathrm{H}_{\mathrm{a}} 、 \mathrm{O}(6)$ 和 $\mathrm{N}(2)-\mathrm{H}$ 附近，第四个水分子必须位于 $8-\mathrm{AG}^{-+}$中 $\mathrm{O}(6)$ 原子附近 的水分子周围，因为如果其位于 $\mathrm{N}(2)-\mathrm{H}$ 附近的水分子 周围后, $\mathrm{N}(1)-\mathrm{H}_{\mathrm{a}}$ 将不会被传递到与 $8-\mathrm{AG}^{-+}$有直接相互 作用的第一水合层，而是被 $\mathrm{N}(1)$ 和其附近水分子中的氧 原子共享; 当我们在 $8-\mathrm{AG}^{\circ+}$ 脱质子模型中将稍微远离 $8-\mathrm{AG}^{\cdot+}$ 的第四个水分子移除后, $8-\mathrm{AG}^{\cdot+}$ 将会发生一个分 子内的质子转移反应, $\mathrm{H}^{+}$最终会从 $8-\mathrm{AG}^{-+}$中的 $\mathrm{N}(1)$ 位 点被转移到 $\mathrm{O}(6)$ 位点; 如果将位于 $\mathrm{N}(2)-\mathrm{H}$ 附近的水分 子移除，虽然 $8-\mathrm{AG}^{\circ}{ }^{+}$脱质子反应路径不会被影响，但是 脱质子反应的能垒会被影响. 进一步的, 在另一个氨基 质子 $\mathrm{N}(2)-\mathrm{H}$ 附近添加第五个水分子后, $8-\mathrm{AG}^{\circ}{ }^{+}$脱质子 反应的过程和能垒都不被影响; 最后, 我们通过添加更 多水分子 $\left(9 \mathrm{H}_{2} \mathrm{O}\right)$ 以更加真实地模拟其微环境得到了 $8-\mathrm{AG}^{++}$脱质子反应的能垒为 $19.5 \mathrm{~kJ} / \mathrm{mol}$.

\section{2 结果与讨论}

\section{$2.18-A G$ 自由基阳离子脱质子反应模型}

对于 DNA 碱基自由基阳离子脱质子反应，早期的 DFT 计算都是在气相中进行的. 如 $\mathrm{Li}$ 等 ${ }^{[25]}$ 在气相条件 下用 B3LYP/6-31+ $\mathrm{G}^{*}$ 方法计算了碱基对 $\mathrm{G}^{*+}$ : C 中的质 子转移反应. 他们发现碱基对 $\mathrm{G}^{\cdot+}: \mathrm{C}$ 比 $\mathrm{G}(-\mathrm{H})^{\circ}:\left(\mathrm{H}^{+}\right) \mathrm{C}$ 更 加稳定, 其能量值相差 $5.9 \mathrm{~kJ} / \mathrm{mol}$; 由此他们预言: $\mathrm{G}^{\circ+}$ : $\mathrm{C}$ 碱基对中位于 $\mathrm{G}$ 碱基上的亚氨基质子 $\mathrm{N}(1)-\mathrm{H}$ 不能通 过氢键转移到与之配对的 $\mathrm{C}$ 碱基上. 然而, $\mathrm{Li}$ 等的理论 计算结果与相关的 $\mathrm{p} K_{\mathrm{a}}$ 分析结果以及 $\mathrm{G}^{\cdot+}: \mathrm{C}$ 碱基对中质 子转移反应很容易发生的实验现象不符. 经过后期的研 究发现: 造成这种不一致的主要原因在于早期的计算忽 略了溶剂分子的环境效应. 当使用 11 个显性水分子来 模拟碱基对 $\mathrm{G}^{+}$: $\mathrm{C}$ 的水合环境时, DFT 计算得到的 $\mathrm{G}(-\mathrm{H})^{\circ}:\left(\mathrm{H}^{+}\right) \mathrm{C}$ 能量比 $\mathrm{G}^{++}: \mathrm{C}$ 低 $5.0 \mathrm{~kJ} / \mathrm{mol}^{[26]}$. 这就很好 地解释了之前的实验结果. 由此可见, DNA 分子体系的 环境效应对于理论描述反应机理是至关重要的. 基于这 样的研究背景, 我们课题组在前期研究 $\mathrm{G}^{\cdot+}$ 在三链 DNA 
中的降解反应以及 $\mathrm{G}^{+}$在 $\mathrm{G}$-四链体中的脱质子反应时, 充分考虑溶剂水分子对单电子氧化过程中形成的稳定 中间体和损伤产物振动频率以及脱质子反应能垒的影 响, 通过添加显性水分子模拟碱基分子附近的微环境, 并且结合极化连续介质模型( $\mathrm{PCM}$ )模拟远离碱基分子的 环境, 最终取得了与实验结果完全一致的结果 ${ }^{[19,27]}$.

为了深入理解 $8-\mathrm{AG}^{\circ}$ 脱质子反应, 揭示溶剂水分 子与 $8-\mathrm{AG}^{+}$相互作用机理, 我们使用密度泛函 M06-2X 方法 ${ }^{[28]}$ 在 $6-31+\mathrm{G}(\mathrm{d})$ 基组水平下对这一过程进行了量 子化学计算. 之所以使用 M06-2X 密度泛函主要是因为: (1) M06-2X 泛函已经被证明在计算包含自由基开壳层 体系的构型及能量时可以取得较好的结果; (2)我们前期 理论与实验研究 $\mathrm{G}^{-+}$在 $\mathrm{G}$-四链体中的脱质子反应时, 使 用 M06-2X 泛函建立的模型取得了与实验值相近的能 垒 ${ }^{[27,29 ~ 31]}$. 溶剂化效应我们也通过添加显性水分子并且 结合 PCM 模型来模拟.

根据文献报道 ${ }^{[32]}$, 在 $\mathrm{G}^{\cdot+}$ 中, 亚氨基质子 $\mathrm{N}(1)-\mathrm{H}$ 的 $\mathrm{p} K_{\mathrm{a}}$ 为 3.9 , 比氨基质子 $\mathrm{N}(2)-\mathrm{H}(4.7)$ 小, 所以 $\mathrm{G}^{\circ+}$ 主 要脱掉亚氨基质子 $\mathrm{N}(1)-\mathrm{H}$, 因此对于 $8-\mathrm{AG}^{*+}$ 脱质子反 应, 我们也主要探讨其脱 $\mathrm{N}(1)-\mathrm{H}$ 的过程. 我们前期在 建立 $\mathrm{G}$-四链体中 $\mathrm{G}^{-+}$脱质子反应模型时发现: 影响 $\mathrm{G}^{-+}$ 脱质子反应能垒的主要是位于脱质子位点附近的水分 子 ${ }^{[27]}$. 因此, 我们首先在 $8-\mathrm{AG}^{\cdot+}$ 中的亚氨基质子 $\mathrm{N}(1)-$ $\mathrm{H}$ 附近可能存在水分子的位置添加了四个水分子, 具体 位置如图 2 所示. 因为亚氨基质子 $\mathrm{N}(1)-\mathrm{H}$ 要从 $8-\mathrm{AG}^{-{ }^{+}}$上脱到水溶液中必须要有质子受体, 所以水分子 $\mathrm{W} 1$ 位于亚氨基质子 $\mathrm{N}(1)-\mathrm{H}$ 附近; 随后我们在水分子 $\mathrm{W} 1$ 附近添加了水分子 $\mathrm{W} 2$ 和 $\mathrm{W} 3$, 其中水分子 $\mathrm{W} 2$ 不但 与 $\mathrm{W} 1$ 之间通过氢键作用, 还与 $8-\mathrm{AG}^{++}$中 $\mathrm{C}(6)=\mathrm{O}$ 中的 氧原子形成氢键, 而水分子 $\mathrm{W} 3$ 位于水分子 $\mathrm{W} 1$ 的另外 一边, 与水分子 $\mathrm{W} 1$ 通过氢键作用, 由于水分子 $\mathrm{W} 3$ 中 氧原子上还存在孤对电子, 所以可以与 $8-\mathrm{AG}^{*+}$ 中环外 氨基上的质子形成氢键; 此外, 因为质子从 $8-\mathrm{AG}^{\circ+}$ 上脱 下来后最终会被传到远离碱基分子的溶液中, 所以我们 在稍微远离 $8-\mathrm{AG}^{-+}$的位置添加了第四个水分子 $\mathrm{W} 4, \mathrm{~W} 4$ 只与水分子 $\mathrm{W} 2$ 形成氢键, 而不与水分子 $\mathrm{W} 1$ 和 $\mathrm{W} 3$ 以 及 $8-\mathrm{AG}^{+}{ }^{+}$形成氢键, 水分子 $\mathrm{W} 4$ 可以帮助水分子 $\mathrm{W} 2$ 将 脱掉的质子稳定在其附近, 如果没有 $\mathrm{W} 4$, 质子将无法 从 $8-\mathrm{AG}^{++}$上脱除(见下文). 我们放置的 4 个水分子实际 上都是位于 $8-\mathrm{AG}^{+}$附近, 这是因为我们主要关注质子 从 $8-\mathrm{AG}^{*+}$ 上转移到第一层水分子中的过程, 而对于质 子从第一层水分子扩散到更外层水中的后续过程我们 并没有进行讨论，因为这一过程类似于已被广泛研究的 纯水中的质子传递过程.

在 $4 \mathrm{H}_{2} \mathrm{O}-\mathrm{PCM}$ 溶剂模型下, 我们优化了 $8-\mathrm{AG}^{\cdot+}$ 脱 质子过程中的反应物、过渡态以及产物的结构, 并得到 了每个结构所对应的相对能量, 构建了 $8-\mathrm{AG}^{-+}$脱质子 反应的势能面. 如图 2 所示. 从图中可以看出被单电子 氧化后的 8-AG(8- $\left.\mathrm{AG}^{-+}\right)$和 4 个 $\mathrm{H}_{2} \mathrm{O}$ 首先通过氢键形成

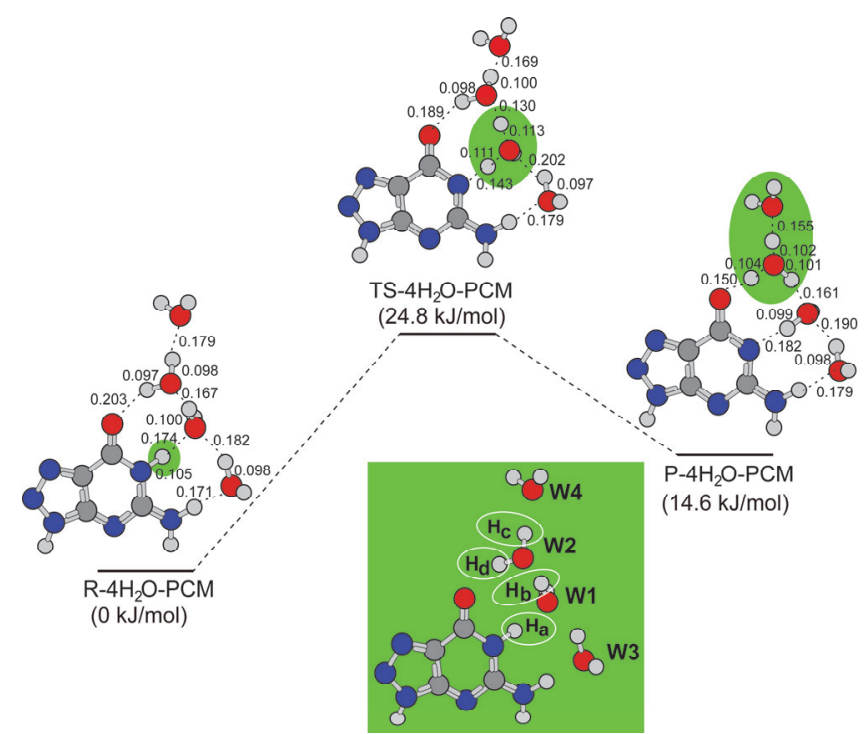

图 $24 \mathrm{H}_{2} \mathrm{O}-\mathrm{PCM}$ 模型中, 在 $\mathrm{M} 06-2 \mathrm{X} / 6-31+\mathrm{G}(\mathrm{d})$ 理论水平上优化得 到的 $8-\mathrm{AG}^{++}$脱质子过程中反应物 $(\mathrm{R})$ 、过渡态 $(\mathrm{TS})$ 以及产物 $(\mathrm{P})$ 的结构 和在 $M 06-2 X / 6-311++G(d, p)$ 理论水平上计算得到的相对能量(所有 的能量都经过零点能校正, 并且以反应物的能量为零点进行校正; 其 中碳、氧、氮和氢原子分别用灰色、红色、蓝色和白色小球表示)

Figure 2 Optimized structures and relative energies obtained at the M06-2X/6-31+G(d) and M06-2X/6-311++G(d,p) level, respectively, for $8-\mathrm{AG}^{\cdot+}$ deprotonation under the $4 \mathrm{H}_{2} \mathrm{O}-\mathrm{PCM}$ model (all energies given are relative to the reactant complex. Carbon, oxygen, nitrogen and hydrogen atoms are denoted with gray, red, blue and white balls, respectively)

了一个复合物 $\mathrm{R}-4 \mathrm{H}_{2} \mathrm{O}-\mathrm{PCM}$. 随着反应的进行, $8-\mathrm{AG}^{\cdot+}$ 中的 $\mathrm{N}(1)-\mathrm{H}_{\mathrm{a}}$ 键的键长逐渐变长, 从 $0.105 \mathrm{~nm}$ 变到 $0.143 \mathrm{~nm}$, 质子逐渐靠近水分子 $\mathrm{W} 1, \mathrm{~N}(1)-\mathrm{H}_{\mathrm{a}}$ 与水分子 $\mathrm{W} 1$ 中的氧原子距离从 $0.174 \mathrm{~nm}$ 缩短到 $0.111 \mathrm{~nm}$, 这促 使水分子 $\mathrm{W} 1$ 中与 $\mathrm{W} 2$ 形成氢键的一个氢原子 $\mathrm{H}_{\mathrm{b}}$ 逐渐 远离 $\mathrm{W} 1$ ，而靠近 $\mathrm{W} 2$ 中的氧原子, $\mathrm{W} 1$ 中氧原子与 $\mathrm{H}_{\mathrm{b}}$ 以 及 $\mathrm{H}_{\mathrm{b}}$ 与 $\mathrm{W} 2$ 中氧原子的键长分别从 $0.100 \mathrm{~nm}$ 和 0.167 $\mathrm{nm}$ 变化到 $0.113 \mathrm{~nm}$ 和 $0.130 \mathrm{~nm}$, 最终形成过渡态 TS-4 $\mathrm{H}_{2} \mathrm{O}-\mathrm{PCM}$. 在 TS- $4 \mathrm{H}_{2} \mathrm{O}-\mathrm{PCM}$ 结构中, $\mathrm{H}_{\mathrm{a}}$ 还未完全 从 $8-\mathrm{AG}^{\circ}$ 的 $\mathrm{N}(1)$ 上脱离, $\mathrm{H}_{\mathrm{b}}$ 被水分子 $\mathrm{W} 1$ 和 $\mathrm{W} 2$ 共享. 经过过渡态 $\mathrm{TS}-4 \mathrm{H}_{2} \mathrm{O}-\mathrm{PCM}$ 后, $\mathrm{H}_{\mathrm{b}}$ 与水分子 $\mathrm{W} 2$ 中氧原 子的距离进一步减小至 $0.101 \mathrm{~nm}$, 相应的 $\mathrm{W} 2$ 中的 $\mathrm{O} \cdots$ $\mathrm{H}_{\mathrm{c}}$ 和 $\mathrm{O} \cdots \mathrm{H}_{\mathrm{d}}$ 键长分别从 $0.100 \mathrm{~nm}$ 和 $0.098 \mathrm{~nm}$ 变化到 $0.102 \mathrm{~nm}$ 和 $0.104 \mathrm{~nm}$, 形成 $\mathrm{H}_{3} \mathrm{O}^{+}$; 同时, $\mathrm{H}_{\mathrm{a}}$ 与 $8-\mathrm{AG}^{\cdot+}$ 中 的 $\mathrm{N}(1)$ 距离进一步增大至 $0.182 \mathrm{~nm}$, 相应的与水分子 W1 中的氧原子距离减小至 $0.099 \mathrm{~nm}$ 最终形成共价键. 至此, 8- $\mathrm{AG}^{\cdot+}$ 中的亚氨基质子 $\mathrm{N}(1)-\mathrm{H}_{\mathrm{a}}$ 从 $\mathrm{N}(1)$ 原子上完 全脱离, 形成脱质子产物 $8-\mathrm{AG}(-\mathrm{H}) \cdot\left(\mathrm{P}-4 \mathrm{H}_{2} \mathrm{O}-\mathrm{PCM}\right)$. 为 了确认势能面中正电荷 $\left(\mathrm{H}^{+}\right)$在各物种上的分布, 我们做 了自然键轨道(Natural Bond Orbital, 简称为 NBO) 分析. 如表 1 所示. 在反应初始时刻, 质子几乎都分布在 $8-\mathrm{AG}^{*+}(0.893|\mathrm{e}|)$, 周围水分子保持中性 $(0.104|\mathrm{e}|)$; 当 形成过渡态分子时, 质子被周围的水分子 $\mathrm{W} 1$ 和 W2 所 共享, $\mathrm{W} 1 \cdots \mathrm{H} \cdots \mathrm{W} 2$ 所带电荷为 $0.763|\mathrm{e}|$; 当形成脱质子 
产物时, 质子已经被转移到 W2 上 $(0.742|\mathrm{e}|)$, 形成 $\mathrm{H}_{3} \mathrm{O}^{+}$. 这一质子迁移路径, 清楚地描述了质子从 $8-\mathrm{AG}^{\cdot+}$ 上转移到第一层水的过程. 考虑到质子在纯水中 的迁移效率极高, 几乎无势垒 ${ }^{[33,34]}$, 因此 $8-\mathrm{AG}^{\cdot+}$ 脱 $\mathrm{N}(1)-\mathrm{H}_{\mathrm{a}}$ 过程主要克服的势垒就是质子转移到第一层 水的能垒, 从势能面中可以看出 $8-\mathrm{AG}^{\circ}$ 脱 $\mathrm{N}(1)-\mathrm{H}_{\mathrm{a}}$ 过 程的能垒为 $24.8 \mathrm{~kJ} / \mathrm{mol}$.

表 $14 \mathrm{H}_{2} \mathrm{O}-\mathrm{PCM}$ 模型下 $8-\mathrm{AG}^{*+}$ 脱质子过程中各结构的电荷分布 $(|\mathrm{e}|)$ Table 1 Charge distribution $(|\mathrm{e}|)$ of species in $8-\mathrm{AG}^{*+}$ deprotonation in $4 \mathrm{H}_{2} \mathrm{O}-\mathrm{PCM}$ model

\begin{tabular}{ccccccc}
\hline & $8-\mathrm{AG}^{+}$ & $\mathrm{W} 1$ & $\mathrm{~W} 1 \cdots \mathrm{H} \cdots \mathrm{W} 2$ & $\mathrm{~W} 2$ & $\mathrm{~W} 3$ & $\mathrm{~W} 4$ \\
\hline $\mathrm{R}$ & 0.893 & 0.023 & - & 0.016 & 0.034 & 0.031 \\
$\mathrm{TS}$ & 0.157 & - & 0.763 & 0.104 & 0.033 & 0.048 \\
$\mathrm{P}$ & 0.12 & 0.035 & - & 0.742 & 0.025 & 0.081 \\
\hline
\end{tabular}

从势能面和 $\mathrm{NBO}$ 分析中我们注意到水分子 W3 和 W4 似乎并没有参与质子迁移过程. 因此我们分别考察 了水分子 $\mathrm{W} 3$ 和 $\mathrm{W} 4$ 对于 $8-\mathrm{AG}^{\circ+}$ 脱质子反应的影响. 首 先, 我们通过建立 $3 \mathrm{H}_{2} \mathrm{O}-\mathrm{PCM}-\mathrm{a}$ 模型考察了第二层水分 子 $\mathrm{W} 4$ 对 $8-\mathrm{AG}^{\cdot+}$ 脱质子反应的影响. 在 $4 \mathrm{H}_{2} \mathrm{O}-\mathrm{PCM}$ 模型 的基础上, 我们直接去掉稍微远离 $8-\mathrm{AG}^{\circ}$ 的水分子 $\mathrm{W} 4$ 构建了 $3 \mathrm{H}_{2} \mathrm{O}-\mathrm{PCM}-\mathrm{a}$ 模型, 势能面如图 3 所示. 在缺少 水分子 W4 时, 在反应初始时刻 $8-\mathrm{AG}^{\cdot+}$ 也会和其附近的 水分子 (W1, W2 和 W3) 形成一个复合物, 这与 $4 \mathrm{H}_{2} \mathrm{O}-\mathrm{PCM}$ 类似. 随着反应的进行 $\mathrm{N}(1)$ 和 $\mathrm{H}_{\mathrm{a}}$ 之间的距 离也会逐渐增大, 从 $0.104 \mathrm{~nm}$ 到 $0.159 \mathrm{~nm}$, 相应的 $\mathrm{H}_{\mathrm{a}}$ 和水分子 $\mathrm{W} 1$ 中氧原子距离从 $0.176 \mathrm{~nm}$ 缩短到 0.104 $\mathrm{nm}$, 而 $\mathrm{H}_{\mathrm{b}}$ 与 $\mathrm{W} 1$ 中氧原子的距离从 $0.099 \mathrm{~nm}$ 增大到 $0.122 \mathrm{~nm}$, 与 $\mathrm{W} 2$ 中氧原子的距离从 $0.173 \mathrm{~nm}$ 缩短到 $0.119 \mathrm{~nm}$, 形成过渡态 TS-3 $\mathrm{H}_{2} \mathrm{O}-\mathrm{PCM}-\mathrm{a}$. 在过渡态 TS- $3 \mathrm{H}_{2} \mathrm{O}-\mathrm{PCM}-\mathrm{a}$ 中 $\mathrm{H}_{\mathrm{a}}$ 也被 $8-\mathrm{AG}^{\cdot+}$ 和 $\mathrm{W} 1$ 共享, $\mathrm{H}_{\mathrm{b}}$ 被 $\mathrm{W} 1$ 和 $\mathrm{W} 2$ 共享. 经过过渡态 TS- $3 \mathrm{H}_{2} \mathrm{O}-\mathrm{PCM}-\mathrm{a}$ 后, 由于缺少 水分子 $\mathrm{W} 4$, 质子并没有像在 $4 \mathrm{H}_{2} \mathrm{O}-\mathrm{PCM}$ 中向着更外层 水传递; 与之相反, $\mathrm{W} 2$ 中的氧原子与 $\mathrm{H}_{\mathrm{c}}$ 之间的距离逐 渐增大, $\mathrm{H}_{\mathrm{c}}$ 逐渐靠近 8- $\mathrm{AG}^{\cdot+}$ 中的 $\mathrm{O}(6)$ 原子, 距离分别从 $0.100 \mathrm{~nm}$ 和 $0.167 \mathrm{~nm}$ 变到 $0.150 \mathrm{~nm}$ 和 $0.104 \mathrm{~nm}, \mathrm{H}_{\mathrm{c}}$ 与 $8-\mathrm{AG}^{\cdot+}$ 中的 $\mathrm{O}(6)$ 原子形成 $\mathrm{H}_{\mathrm{c}}-\mathrm{O}$ 键, 最终形成产物 $\mathrm{P}-3 \mathrm{H}_{2} \mathrm{O}-\mathrm{PCM}-\mathrm{a}$. 我们可以清楚地从势能面中看到, 在 缺少水分子 $\mathrm{W} 4$ 时, 单电子氧化 8-AG 形成 8- $\mathrm{AG}^{\circ+}$ 后将 会发生分子内的质子转移过程. 为了确认这一分子内质 子转移过程, 我们也进行了相应的 NBO 分析. 如表 2 所 示, 在反应初始时刻, 质子几乎都分布在 $8-\mathrm{AG}^{\cdot+}$ $(0.899|\mathrm{e}|)$, 周围水分子保持中性 $(0.099|\mathrm{e}|)$; 当形成过渡 态分子时, 质子被周围的水分子 $\mathrm{W} 1$ 和 W2 所共享, $\mathrm{W} 1 \cdots \mathrm{H} \cdots \mathrm{W} 2$ 所带电荷为 $0.834|\mathrm{e}|$; 当形成脱质子产物 时, 质子已经被转移到 $8-\mathrm{AG}^{\cdot+}$ 上 $(0.842|\mathrm{e}|)$, 与 $\mathrm{O}(6)$ 原子 形成 $\mathrm{O}-\mathrm{H}$ 键. 从势能面上可进一步看出, 该分子内质 子转移过程的能垒为 $37.6 \mathrm{~kJ} / \mathrm{mol}$. 由此可以确认: 在构 建 $8-\mathrm{AG}^{\cdot+}$ 脱质子反应模型时在稍微远离 $8-\mathrm{AG}^{\cdot+}$ 而更加
靠近更外层水的位置添加水分子 W4 的必要性.

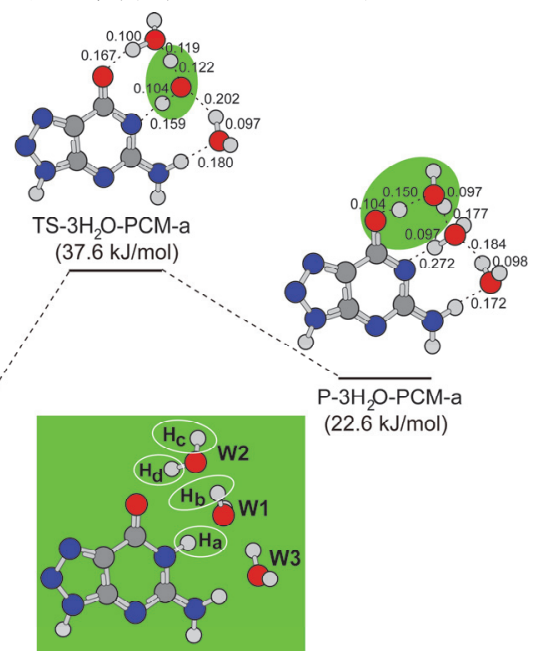

图 $33 \mathrm{H}_{2} \mathrm{O}-\mathrm{PCM}-\mathrm{a}$ 模型中, 在 $\mathrm{M} 06-2 \mathrm{X} / 6-31+\mathrm{G}(\mathrm{d})$ 理论水平上优化得 到的 $8-\mathrm{AG}^{++}$脱质子过程中反应物 $(\mathrm{R})$ 、过渡态 $(\mathrm{TS})$ 以及产物 $(\mathrm{P})$ 的结构 和在 $\mathrm{M} 06-2 \mathrm{X} / 6-311++\mathrm{G}(\mathrm{d}, \mathrm{p})$ 理论水平上计算得到的相对能量(所有 的能量都经过零点能校正, 并且以反应物的能量为零点进行校正; 其 中碳、氧、氮和氢原子分别用灰色、红色、蓝色和白色小球表示)

Figure 3 Optimized structures and relative energies obtained at the M06-2X/6-31+G(d) and M06-2X/6-311++G(d,p) level, respectively, for $8-\mathrm{AG}^{-+}$deprotonation under the $3 \mathrm{H}_{2} \mathrm{O}-\mathrm{PCM}$-a model (all energies given are relative to the reactant complex. Carbon, oxygen, nitrogen and hydrogen atoms are denoted with gray, red, blue and white balls, respectively)

表 $23 \mathrm{H}_{2} \mathrm{O}-\mathrm{PCM}-\mathrm{a}$ 模型下 $8-\mathrm{AG}^{++}$脱质子过程中各结构的电荷分布 (|e|)

Table 2 Charge distribution $(|\mathrm{e}|)$ of species in $8-\mathrm{AG}^{*+}$ deprotonation in $3 \mathrm{H}_{2} \mathrm{O}-\mathrm{PCM}-\mathrm{a}$ model

\begin{tabular}{cccccc}
\hline & $8-\mathrm{AG}^{++}$ & $\mathrm{W} 1$ & $\mathrm{~W} 1 \cdots \mathrm{H}^{\cdots} \cdots \mathrm{W} 2$ & $\mathrm{~W} 2$ & $\mathrm{~W} 3$ \\
\hline $\mathrm{R}$ & 0.899 & 0.033 & - & 0.031 & 0.035 \\
$\mathrm{TS}$ & 0.134 & - & 0.834 & 0.167 & 0.031 \\
$\mathrm{P}$ & 0.842 & 0.055 & - & 0.072 & 0.031 \\
\hline
\end{tabular}

随后我们探讨了水分子 $\mathrm{W} 3$ 在 $8-\mathrm{AG}^{-+}$脱质子反应 中的作用. 我们在 $4 \mathrm{H}_{2} \mathrm{O}-\mathrm{PCM}$ 模型的基础上通过去掉水 分子 W3 建立了 $3 \mathrm{H}_{2} \mathrm{O}-\mathrm{PCM}-\mathrm{b}$ 模型，其势能面如图 4 所 示. 从图中可以看出, 当水分子 $\mathrm{W} 3$ 不存在时, 亚氨基 质子 $\mathrm{H}_{\mathrm{a}}$ 从 $8-\mathrm{AG}^{\cdot+}$ 上传到更外层水的路径与 $4 \mathrm{H}_{2} \mathrm{O}-\mathrm{PCM}$ 模型基本一致. 首先都是由水分子和 $8-\mathrm{AG}^{\cdot+}$ 形成一个 复合物 (R-3 $\left.\mathrm{H}_{2} \mathrm{O}-\mathrm{PCM}-\mathrm{b}\right)$, 随着 $8-\mathrm{AG}^{\bullet+}$ 中 $\mathrm{N}(1)-\mathrm{H}_{\mathrm{a}}$ 键断 裂, $\mathrm{H}_{\mathrm{a}}$ 被传递到 $\mathrm{W} 1$ 中氧原子附近，同时 $\mathrm{W} 1$ 中的 $\mathrm{O} \cdots$ $\mathrm{H}_{\mathrm{b}}$ 键键长逐渐增大, 当 $\mathrm{H}_{\mathrm{b}}$ 被 $\mathrm{W} 1$ 和 $\mathrm{W} 2$ 中的氧原子共享 时形成过渡态 TS-3 $\mathrm{H}_{2} \mathrm{O}-\mathrm{PCM}-\mathrm{b}$; 经过过渡态后, 质子会 进一步向水分子 $\mathrm{W} 2$ 传递并通过形成 $\mathrm{H}_{3} \mathrm{O}^{+}$被稳定在水 分子 W2 附近, 最终形成脱质子产物 8-AG(-H) $\left(\mathrm{P}-3 \mathrm{H}_{2} \mathrm{O}-\mathrm{PCM}-\mathrm{b}\right)$. $\mathrm{NBO}$ 分析也确认了这一质子转移过 程(表 $\mathrm{S} 1$ ). 但同时我们从势能面图上也可以看出, 在 $3 \mathrm{H}_{2} \mathrm{O}-\mathrm{PCM}-\mathrm{b}$ 模型中, $8-\mathrm{AG}^{\cdot+}$ 脱质子过程的能垒只有 $16.3 \mathrm{~kJ} / \mathrm{mol}$, 要比 $4 \mathrm{H}_{2} \mathrm{O}-\mathrm{PCM}$ 模型中小 $8.5 \mathrm{~kJ} / \mathrm{mol}$. $3 \mathrm{H}_{2} \mathrm{O}-\mathrm{PCM}-\mathrm{b}$ 模型的结果说明: 虽然水分子 W3 不影响 脱质子反应路径, 但是会通过对水分子 W1 产生一个牵 
引力从而影响脱质子反应的能垒, 所以在建立 $8-\mathrm{AG}^{\cdot+}$ 脱质子反应模型时在 $8-\mathrm{AG}^{\circ}$ 环外氨基附近添加水分子 W3 也很有必要.

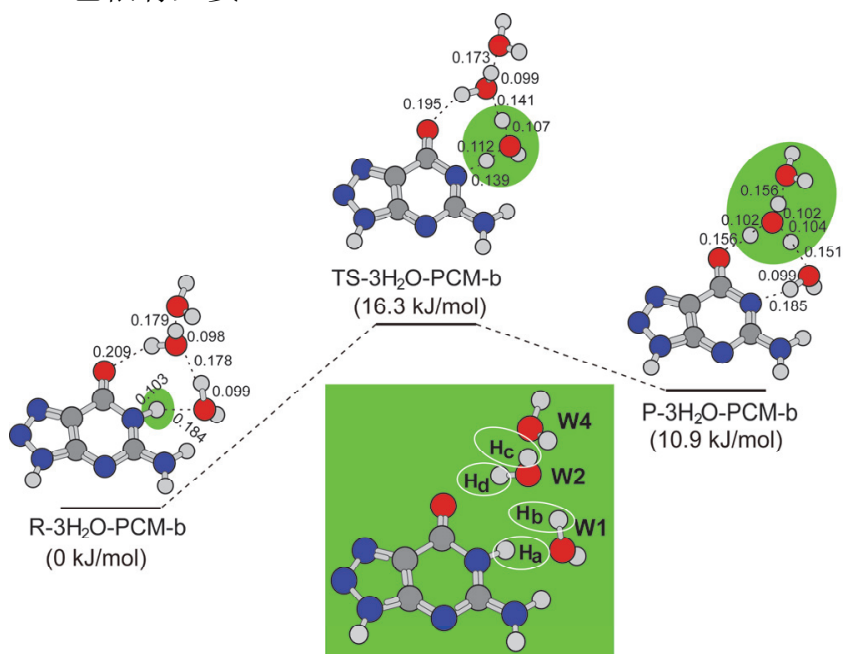

图 $43 \mathrm{H}_{2} \mathrm{O}-\mathrm{PCM}-\mathrm{b}$ 模型中, 在 $\mathrm{M} 06-2 \mathrm{X} / 6-31+\mathrm{G}(\mathrm{d})$ 理论水平上优化得 到的 $8-\mathrm{AG}^{+}$脱质子过程中反应物 $(\mathrm{R})$ 、过渡态 $(\mathrm{TS})$ 以及产物 $(\mathrm{P})$ 的结构 和在 $\mathrm{M} 06-2 \mathrm{X} / 6-311++\mathrm{G}(\mathrm{d}, \mathrm{p})$ 理论水平上计算得到的相对能量(所有 的能量都经过零点能校正, 并且以反应物的能量为零点进行校正; 其 中碳、氧、氮和氢原子分别用灰色、红色、蓝色和白色小球表示)

Figure 4 Optimized structures and relative energies obtained at the $\mathrm{M} 06-2 \mathrm{X} / 6-31+\mathrm{G}(\mathrm{d})$ and $\mathrm{M} 06-2 \mathrm{X} / 6-311++\mathrm{G}(\mathrm{d}, \mathrm{p})$ level, respectively, for $8-\mathrm{AG}^{++}$deprotonation under the $3 \mathrm{H}_{2} \mathrm{O}-\mathrm{PCM}-\mathrm{b}$ model (all energies given are relative to the reactant complex. Carbon, oxygen, nitrogen and hydrogen atoms are denoted with gray, red, blue and white balls, respectively)

此外, 我们还同时去掉水分子 W3 和 W4, 建立了 $2 \mathrm{H}_{2} \mathrm{O}-\mathrm{PCM}$ 模型. 令我们意外的是, 在只有水分子 $\mathrm{W} 1$ 和 W2 时, $8-\mathrm{AG}^{*+}$ 并没有像在 $3 \mathrm{H}_{2} \mathrm{O}-\mathrm{PCM}-\mathrm{a}$ 模型中因缺 少更外层水分子 W4 而发生一个分子内的质子转移过 程, 与之对应的是质子最终传递到水分子 W2 附近, 并 被水分子 $\mathrm{W} 2$ 稳定, 形成 $\mathrm{H}_{3} \mathrm{O}^{+}$, 如图 5 中 $\mathrm{P}-2 \mathrm{H}_{2} \mathrm{O}-\mathrm{PCM}$ 所示. 在 $\mathrm{P}-2 \mathrm{H}_{2} \mathrm{O}-\mathrm{PCM}$ 中, $\mathrm{H}_{\mathrm{b}}$ 和 $\mathrm{H}_{\mathrm{d}}$ 与水分子 $\mathrm{W} 2$ 中的氧 原子距离分别为 $0.108 \mathrm{~nm}$ 和 $0.105 \mathrm{~nm}$, 而 $\mathrm{H}_{\mathrm{c}}$ 与 $\mathrm{W} 2$ 中 的氧原子距离因为没有更外层水分子的存在, 所以没有 相应的变长, 为 $0.098 \mathrm{~nm}$; 这进一步说明更外层水分子 $\mathrm{W} 4$ 的重要性. 此外, 在 $2 \mathrm{H}_{2} \mathrm{O}-\mathrm{PCM}$ 模型中, $8-\mathrm{AG}^{\cdot+}$ 脱质 子过程形成的过渡态也与 $4 \mathrm{H}_{2} \mathrm{O}-\mathrm{PCM}$ 中不同. 在 TS- $2 \mathrm{H}_{2} \mathrm{O}-\mathrm{PCM}$ 中, $\mathrm{H}_{\mathrm{a}}$ 并没有被 $8-\mathrm{AG}^{-+}$与 $\mathrm{W} 1$ 共享, 而是 直接与 $\mathrm{W} 1$ 中的氧原子成键 $(0.101 \mathrm{~nm})$, 与之对应的是 $\mathrm{H}_{\mathrm{b}}$ 更靠近 $\mathrm{W} 2$ 中的氧原子, 与 $\mathrm{W} 1$ 和 W2 中氧原子的距 离分别为 $0.127 \mathrm{~nm}$ 和 $0.115 \mathrm{~nm}$, 这和 $4 \mathrm{H}_{2} \mathrm{O}-\mathrm{PCM}$ 模型中 正好相反. 在 $4 \mathrm{H}_{2} \mathrm{O}-\mathrm{PCM}$ 模型的过渡态中 $\mathrm{H}_{\mathrm{b}}$ 更靠近 $\mathrm{W} 1$ 中的氧原子, 而非 $\mathrm{W} 2$ 中的氧原子. 同样的, 我们在 $2 \mathrm{H}_{2} \mathrm{O}-\mathrm{PCM}$ 中也进行了 $\mathrm{NBO}$ 分析, 确认了这一过程中 质子转移的路径, 如表 $\mathrm{S} 2$ 所示. 在 $2 \mathrm{H}_{2} \mathrm{O}-\mathrm{PCM}$ 中, 质子 虽然与 $4 \mathrm{H}_{2} \mathrm{O}-\mathrm{PCM}$ 一样被最终稳定在水分子 W2 附近, 但是由于在 $2 \mathrm{H}_{2} \mathrm{O}-\mathrm{PCM}$ 中缺少更外层的水分子 $\mathrm{W} 4$, 稳 定在 W2 附近的质子将不会被进一步的传递到溶剂相
中，这是与实际情况不相符的.

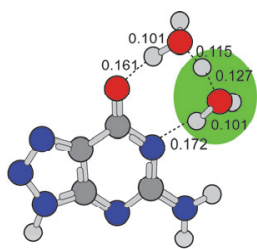

TS-2 $\mathrm{H}_{2} \mathrm{O}-\mathrm{PCM}$ $(29.1 \mathrm{~kJ} / \mathrm{mol})$
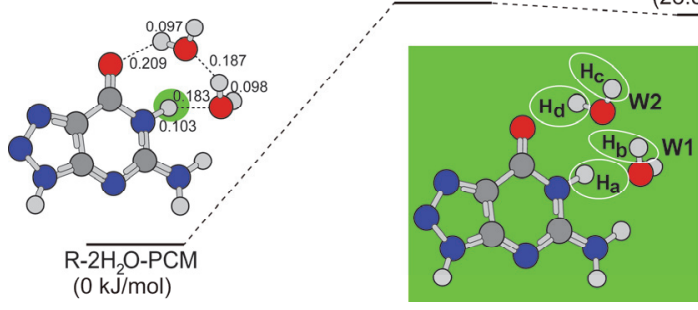

图 $52 \mathrm{H}_{2} \mathrm{O}-\mathrm{PCM}$ 模型中, 在 $\mathrm{M} 06-2 \mathrm{X} / 6-31+\mathrm{G}(\mathrm{d})$ 理论水平上优化得 到的 $8-\mathrm{AG}^{++}$脱质子过程中反应物 $(\mathrm{R})$ 、过渡态 $(\mathrm{TS})$ 以及产物 $(\mathrm{P})$ 的结构 和在 $\mathrm{M} 062 \mathrm{X} / 6-311++\mathrm{G}(\mathrm{d}, \mathrm{p})$ 理论水平上计算得到的相对能量(所有 的能量都经过零点能校正, 并且以反应物的能量为零点进行校正; 其 中碳、氧、氮和氢原子分别用灰色、红色、蓝色和白色小球表示)

Figure 5 Optimized structures and relative energies obtained at the $\mathrm{M} 06-2 \mathrm{X} / 6-31+\mathrm{G}(\mathrm{d})$ and $\mathrm{M} 06-2 \mathrm{X} / 6-311++\mathrm{G}(\mathrm{d}, \mathrm{p})$ level, respectively, for $8-\mathrm{AG}^{-+}$deprotonation under the $2 \mathrm{H}_{2} \mathrm{O}-\mathrm{PCM}$ model (all energies given are relative to the reactant complex. Carbon, oxygen, nitrogen and hydrogen atoms are denoted with gray, red, blue and white balls, respectively)

随后, 我们对稍微远离 $8-\mathrm{AG}^{\circ+}$ 的水分子 $\mathrm{W} 4$ 的位置 进行了研究. 我们注意到水分子 W4 除可以位于水分子 W2 附近之外，还可以被放置到水分子 W3 附近. 基于 此, 我们建立了 $4 \mathrm{H}_{2} \mathrm{O}-\mathrm{PCM}-\mathrm{a}$ 模型, 在此模型下优化得 到的反应物、过渡态及产物的构型及势能面如图 6 所示. 为了与 $4 \mathrm{H}_{2} \mathrm{O}-\mathrm{PCM}$ 中的第四个水分子进行区分, 在此模 型中加入的第四个水分子我们定义为 $\mathrm{W} 4^{\prime}$. 从图 6 中可 以看出：在反应的初始阶段, $8-\mathrm{AG}^{\circ+}$ 与 4 个水分子也会 形成一个复合物 (R-4 $\left.\mathrm{H}_{2} \mathrm{O}-\mathrm{PCM}-\mathrm{a}\right)$, 随着反应的进行, $8-\mathrm{AG}^{\cdot+}$ 中的亚氨基质子 $\mathrm{H}_{\mathrm{a}}$ 与 $\mathrm{N}(1)$ 之间的距离从 0.107 $\mathrm{nm}$ 增加至 $0.139 \mathrm{~nm}$, 而更靠近水分子 $\mathrm{W} 1$ 中的氧原子 $(0.113 \mathrm{~nm})$. 与 $4 \mathrm{H}_{2} \mathrm{O}-\mathrm{PCM}$ 中不同的是, 在 $4 \mathrm{H}_{2} \mathrm{O}-\mathrm{PCM}-\mathrm{a}$ 模型中我们并没有观察到水分子 $\mathrm{W} 1$ 中的 $\mathrm{O} \cdots \mathrm{H}$ 键键长 发生明显变化, 在 R- $4 \mathrm{H}_{2} \mathrm{O}-\mathrm{PCM}-\mathrm{a}$ 中分别为 $0.098 \mathrm{~nm}$ 和 $0.098 \mathrm{~nm}$, 在过渡态 TS- $4 \mathrm{H}_{2} \mathrm{O}-\mathrm{PCM}-\mathrm{a}$ 中为 $0.101 \mathrm{~nm}$ 和 $0.100 \mathrm{~nm}, \mathrm{H}_{\mathrm{a}}$ 被 $\mathrm{N}(1)$ 与 $\mathrm{W} 1$ 中的 $\mathrm{O}$ 原子所共享. 经过过 渡态后，质子并没有像 $4 \mathrm{H}_{2} \mathrm{O}-\mathrm{PCM}$ 中一样进一步传递到 $\mathrm{W} 2$, 并以 $\mathrm{H}_{3} \mathrm{O}^{+}$的形式被稳定在 $\mathrm{W} 2$ 上, 而是仍然处于 $\mathrm{N}(1)$ 和 $\mathrm{W} 1$ 中氧原子之间, 距离分别为 $0.143 \mathrm{~nm}$ 和 0.110 $\mathrm{nm}$, 产物结构 $\left(\mathrm{P}-4 \mathrm{H}_{2} \mathrm{O}-\mathrm{PCM}-\mathrm{a}\right)$ 与过渡态结构基本类似. $\mathrm{NBO}$ 分析的结果也显示在反应物中质子完全位于 $8-\mathrm{AG}^{\cdot+}$ 上 $(0.883|\mathrm{e}|)$, 周围水分子保持中性 $(0.118|\mathrm{e}|)$; 当 形成过渡态分子时, 质子被 $8-\mathrm{AG}^{*}{ }^{+}$和 $\mathrm{W} 1$ 所共享 $(0.877$ $|\mathrm{e}|)$; 当形成产物时, 质子仍然被 $8-\mathrm{AG}^{\circ+}$ 和 $\mathrm{W} 1$ 所共享 $(0.862|\mathrm{e}|)$ (表 3). 这些结果意味着质子 $\mathrm{H}_{\mathrm{a}}$ 并没有被完全 
传递到离 $8-\mathrm{AG}^{\circ}$ 最近的第一层水中. $4 \mathrm{H}_{2} \mathrm{O}-\mathrm{PCM}-\mathrm{a}$ 模型 的结果表明在建立 $8-\mathrm{AG}^{\cdot+}$ 脱质子反应模型时, 稍微远 离 $8-\mathrm{AG}^{\cdot+}$ 的第四个水分子应该添加在水分子 $\mathrm{W} 2$ 附近, 而非水分子 $\mathrm{W} 3$ 附近. 实际上, 从 $4 \mathrm{H}_{2} \mathrm{O}-\mathrm{PCM}-\mathrm{a}$ 模型中 可以看出, 当质子从 $8-\mathrm{AG}^{\cdot+}$ 的 $\mathrm{N}(1)$ 原子上失去之后, 有 两个潜在的迁移方向, 分别为: (1)经过 W1 到 W2; (2)经 过 W1 到 W3; 虽然在此模型中水分子 W2 附近并没有 放置第二层水分子, 但是根据我们上文建立的 $3 \mathrm{H}_{2} \mathrm{O}-\mathrm{PCM}-\mathrm{a}$ 模型，第二层水分子 $\mathrm{W} 4$ 主要作用是将质 子稳定在 $\mathrm{W} 2$ 附近, 质子 $\mathrm{H}_{\mathrm{a}}$ 是满足向这两个方向传递的 条件的; 然而, $\mathrm{H}_{\mathrm{a}}$ 并没有沿着这样的路径去传递, 而是 被最终稳定在 W1 附近, 所以可以确定 $8-\mathrm{AG}^{\cdot+}$ 脱 $\mathrm{N}(1)$ $-\mathrm{H}_{\mathrm{a}}$ 有一定的方向性.

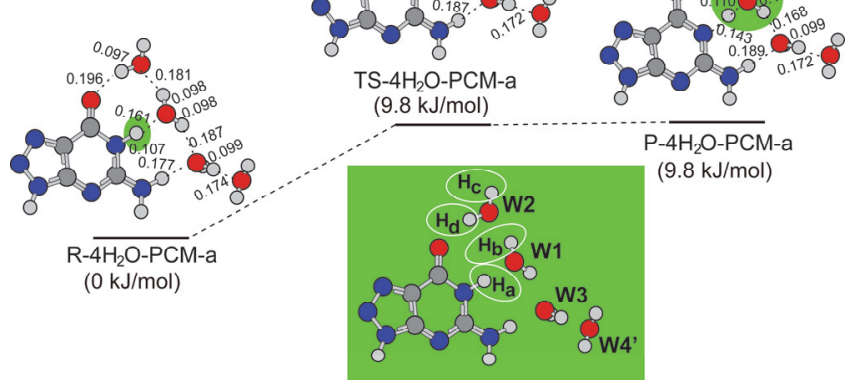

图 $64 \mathrm{H}_{2} \mathrm{O}-\mathrm{PCM}-\mathrm{a}$ 模型中, 在 M06-2X/6-31+G(d)理论水平上优化得 到的 $8-\mathrm{AG}^{*}$ 脱质子过程中反应物 $(\mathrm{R})$ 、过渡态 $(\mathrm{TS})$ 以及产物 $(\mathrm{P})$ 的结构 和在 $\mathrm{M} 062 \mathrm{X} / 6-311++\mathrm{G}(\mathrm{d}, \mathrm{p})$ 理论水平上计算得到的相对能量(所有 的能量都经过零点能校正, 并且以反应物的能量为零点进行校正; 其 中碳、氧、氮和氢原子分别用灰色、红色、蓝色和白色小球表示)

Figure 6 Optimized structures and relative energies obtained at the $\mathrm{M} 06-2 \mathrm{X} / 6-31+\mathrm{G}(\mathrm{d})$ and $\mathrm{M} 06-2 \mathrm{X} / 6-311++\mathrm{G}(\mathrm{d}, \mathrm{p})$ level, respectively, for $8-\mathrm{AG}^{++}$deprotonation under the $4 \mathrm{H}_{2} \mathrm{O}-\mathrm{PCM}$-a model (all energies given are relative to the reactant complex. Carbon, oxygen, nitrogen and hydrogen atoms are denoted with gray, red, blue and white balls, respectively)

表 $34 \mathrm{H}_{2} \mathrm{O}-\mathrm{PCM}-\mathrm{a}$ 模型下 $8-\mathrm{AG}^{+}$脱质子过程中各结构的电荷分布 $(|\mathrm{e}|)$

Table 3 Charge distribution (|e|) of species in $8-\mathrm{AG}^{\cdot+}$ deprotonation in $4 \mathrm{H}_{2} \mathrm{O}-\mathrm{PCM}$-a model

\begin{tabular}{ccccccc}
\hline & $8-\mathrm{AG}^{+}$ & $\mathrm{W} 1$ & $\mathrm{~W} 1 \cdots \mathrm{H}^{*} \mathrm{~W} 2$ & $\mathrm{~W} 2$ & $\mathrm{~W} 3$ & $\mathrm{~W}^{\prime}$ \\
\hline $\mathrm{R}$ & 0.883 & 0.034 & - & 0.017 & 0.028 & 0.039 \\
$\mathrm{TS}$ & 0.184 & 0.693 & - & 0.050 & 0.038 & 0.044 \\
$\mathrm{P}$ & 0.167 & 0.695 & - & 0.054 & 0.040 & 0.044 \\
\hline
\end{tabular}

接着, 我们在 $4 \mathrm{H}_{2} \mathrm{O}-\mathrm{PCM}$ 模型的基础上继续添加了 一个水分子建立了 $5 \mathrm{H}_{2} \mathrm{O}-\mathrm{PCM}$ 模型, 以验证更多的水分 子是否会对 $8-\mathrm{AG}^{\cdot+}$ 脱质子路径和能垒产生影响. 第五 个水分子我们添加在水分子 $\mathrm{W} 3$ 附近, 并与 $8-\mathrm{AG}^{\circ+}$ 中环 外氨基上另外一个 $\mathrm{N}(2)-\mathrm{H}$ 形成氢键. 之所以这么添加 水分子主要是考虑到要将水分子包含在已经添加的四 个水分子的氢键网络中, 如果添加的水分子不在氢键网 络中, 将不可能会对 $8-\mathrm{AG}^{\circ}$ 脱质子路径和能垒产生大
的影响. 势能面如图 S1 所示. 从图中我们可以看出第五 个水分子的添加并没有影响 $8-\mathrm{AG}^{-+}$脱质子反应的路径, 亚氨基质子 $\mathrm{N}(1)-\mathrm{H}$ 都是通过水分子 $\mathrm{W} 1$ 的传递最终被 稳定在 $\mathrm{W} 2$ 附近形成 $\mathrm{H}_{3} \mathrm{O}^{+}$, 相应的脱质子反应能垒也 只是从 $24.8 \mathrm{~kJ} / \mathrm{mol}$ 变化到 $25.5 \mathrm{~kJ} / \mathrm{mol}$, 表明第五个水分 子的加入对 $8-\mathrm{AG}^{\cdot+}$ 脱质子反应的能垒影响已经很小. 这进一步表明: 描述亚氨基质子从 $8-\mathrm{AG}^{\circ}{ }^{+}$上脱到溶液 中只需要 4 个水分子, 但是如果要得到更加精确的脱质 子能垒则需要添加更多的水分子, 因为第五个水分子的 加入还是使脱质子能垒发生了微小变化.

\subsection{8-AG 自由基阳离子脱质子反应能垒}

根据之前的研究, 在 DNA 碱基分子中, 溶剂水分 子大部分都是位于 $\mathrm{N}, \mathrm{O}$ 等原子附近. 所以, 为了得到更 加精确的 $8-\mathrm{AG}^{*+}$ 脱质子反应能垒, 我们在 $4 \mathrm{H}_{2} \mathrm{O}-\mathrm{PCM}$ 的基础上继续在 $\mathrm{N}(2)-\mathrm{H}, \mathrm{N}(3), \mathrm{O}(6), \mathrm{N}(7)$ 和 $\mathrm{N}(8)$ 等原 子附近添加了 5 个水分子, 以尽可能真实地模拟 $8-\mathrm{AG}^{++}$周围的水环境, 建立了 $9 \mathrm{H}_{2} \mathrm{O}-\mathrm{PCM}$ 模型, 如图 7 所示. 我们并没有在 $\mathrm{N}(9)-\mathrm{H}$ 附近添加水分子，这主要是 因为在碱基分子中，N(9)位置一般会被戊糖基取代，水 分子不可能在 $\mathrm{N}(9)$ 附近与之形成氢键. 从优化的反应 物、过渡态及产物的构型可以看出, $8-\mathrm{AG}^{+}{ }^{+}$脱质子反应 的路径并没有因为在以上位置增加额外的水分子而被 改变, 与 $4 \mathrm{H}_{2} \mathrm{O}-\mathrm{PCM}$ 模型中一样, 这意味着亚氨基质子 $\mathrm{H}_{\mathrm{a}}$ 可以从 $8-\mathrm{AG}^{\circ+}$ 上传递到离 $8-\mathrm{AG}^{\circ+}$ 最近的第一层水中. 相应的 NBO 分析结果也证实了这一结果, 如表 S3. 通 过 $9 \mathrm{H}_{2} \mathrm{O}-\mathrm{PCM}$ 模型下建立的势能面我们得到 $8-\mathrm{AG}^{\circ+}$ 脱 质子反应的能垒为 $19.5 \mathrm{~kJ} / \mathrm{mol}$, 比直接用 $4 \mathrm{H}_{2} \mathrm{O}-\mathrm{PCM}$ 模

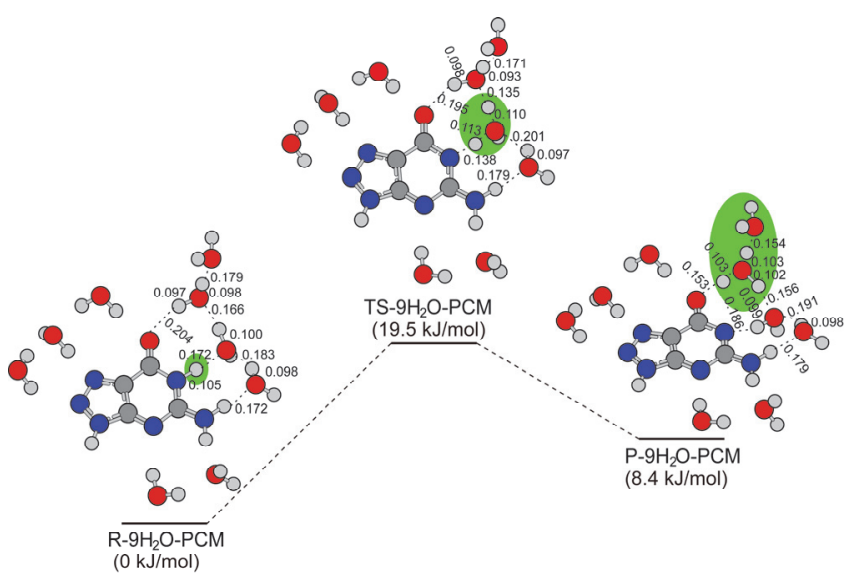

图 $79 \mathrm{H}_{2} \mathrm{O}-\mathrm{PCM}$ 模型中, 在 $\mathrm{M} 06-2 \mathrm{X} / 6-31+\mathrm{G}(\mathrm{d})$ 理论水平上优化得 到的 $8-\mathrm{AG}^{+}{ }^{+}$脱质子过程中反应物 $(\mathrm{R})$ 、过渡态 $(\mathrm{TS})$ 以及产物 $(\mathrm{P})$ 的结构 和在 $\mathrm{M} 06-2 \mathrm{X} / 6-311++\mathrm{G}(\mathrm{d}, \mathrm{p})$ 理论水平上计算得到的相对能量(所有 的能量都经过零点能校正, 并且以反应物的能量为零点进行校正; 其 中碳、氧、氮和氢原子分别用灰色、红色、蓝色和白色小球表示)

Figure 7 Optimized structures and relative energies obtained at the $\mathrm{M} 06-2 \mathrm{X} / 6-31+\mathrm{G}(\mathrm{d})$ and $\mathrm{M} 06-2 \mathrm{X} / 6-311++\mathrm{G}(\mathrm{d}, \mathrm{p})$ level, respectively, for $8-\mathrm{AG}^{\cdot+}$ deprotonation under the $9 \mathrm{H}_{2} \mathrm{O}-\mathrm{PCM}$ model (all energies given are relative to the reactant complex. Carbon, oxygen, nitrogen and hydrogen atoms are denoted with gray, red, blue and white balls, respectively) 
型得到的能垒低 $5.3 \mathrm{~kJ} / \mathrm{mol}$, 能垒的变化可能是源于不 同模型中 $8-\mathrm{AG}^{\cdot+}$ 中 $\mathrm{N}(1)$ 的给质子能力以及 $\mathrm{N}(1)-\mathrm{H}$ 附 近水分子中 $\mathrm{O}$ 的接受质子能力不同.

值得注意的是, 我们从 $9 \mathrm{H}_{2} \mathrm{O}-\mathrm{PCM}$ 模型中得到的 $8-\mathrm{AG}^{\cdot+}$ 脱质子反应能垒只是相对于 $4 \mathrm{H}_{2} \mathrm{O}-\mathrm{PCM}$ 和 $5 \mathrm{H}_{2} \mathrm{O}-\mathrm{PCM}$ 中的更加精确. 在本工作中, 为了节省计算 机时, 我们建立的所有 $8-\mathrm{AG}^{\cdot+}$ 脱质子模型都没有考虑 磷酸和龙糖对能垒的影响, 并且只是考虑了与 $8-\mathrm{AG}^{\cdot+}$ 有直接相互作用的水分子. 所以, 如果想要得到与实际 更加接近的 $8-\mathrm{AG}^{*+}$ 脱质子反应能垒则需要在实验基础 上建立更加接近实际情况的模型.

\section{3 结论}

在本工作中, 我们首先通过密度泛函理论, 在 $\mathrm{M} 06-2 \mathrm{X} / 6-31+\mathrm{G}(\mathrm{d})$ 理论水平上建立了 $8-\mathrm{AG}^{\cdot+}$ 脱亚氨基 质子 $\mathrm{N}(1)-\mathrm{H}$ 反应模型, 其中溶剂化效应通过显性水分 子与 PCM 模型结合来模拟. 我们的结果显示要模拟 $8-\mathrm{AG}^{\cdot+}$ 脱质子反应过程至少需要 4 个显性水分子. 其中 3 个水分子分别位于 $\mathrm{N}(1)-\mathrm{H}_{\mathrm{a}}$, 环外氨基质子 $\mathrm{N}(2)-\mathrm{H}$ 以及 $\mathrm{O}(6)$ 原子附近，与 $8-\mathrm{AG}^{\cdot+}$ 直接通过氢键作用; 第四 个水分子必须位于稍微远离 $8-\mathrm{AG}^{\circ+}$ 的第二水合层, 如 果缺少第二水合层的水分子, 质子将不能从 $8-\mathrm{AG}^{+}$中 的 $\mathrm{N}(1)-\mathrm{H}_{\mathrm{a}}$ 传递到溶液中; 与之对应, 其将会把 $\mathrm{N}(1)$ $-\mathrm{H}_{\mathrm{a}}$ 通过一个分子内质子转移过程转移到 $\mathrm{O}(6)$ 原子上 或者稳定在 $\mathrm{O}(6)$ 原子附近的水分子周围; 此外, 对于第 二层水的位置其必须位于 $\mathrm{O}(6)$ 原子附近的水分子周围, 如果将第二层水分子添加到环外氨基质子 $\mathrm{N}(2)-\mathrm{H}$ 附 近的水分子周围, $\mathrm{N}(1)-\mathrm{H}_{\mathrm{a}}$ 将不能从 $8-\mathrm{AG}^{\cdot+}$ 上脱到溶液 中, $\mathrm{N}(1)-\mathrm{H}_{\mathrm{a}}$ 将被 $8-\mathrm{AG}^{\cdot+}$ 和其附近的水分子共享; 虽然 环外氨基质子 $\mathrm{N}(2)-\mathrm{H}$ 附近的水分子不影响脱质子反 应的路径, 但是其会对 $8-\mathrm{AG}^{\cdot+}$ 脱质子反应的能垒产生 影响. 最后, 我们通过添加更多的水分子尽可能模拟 $8-\mathrm{AG}^{\cdot+}$ 周围真实的水环境得到了 $8-\mathrm{AG}^{\cdot+}$ 脱质子反应的 能垒为 $19.5 \mathrm{~kJ} / \mathrm{mol}$. 我们的这些结果将有助于更加深入 地了解 8-AG 的物理化学性质, 并且为揭示 DNA 单电子 氧化损伤机理提供进一步的理论基础.

\section{4 实验部分}

反应物、过渡态和产物的优化构型及自然键轨道 (NBO)结果均在 M06-2X/6-31+G(d)理论水平上计算获 得. 通过振动频率分析确认反应物和产物无虚频, 过渡 态有且仅有一个虚频. 在此基础之上, 依据反应途径的 内禀反应坐标(IRC)理论, 进行了相应的极小能量途径 计算, 以正确关联过渡态和相应的反应物和产物. 计算 中的溶剂效应采用显性水分子结合经典的极化连续介 质模型(PCM)进行模拟. 为了获得更加精确的能量, 我 们还使用了 6-311++G(d,p)基组对计算结果进行了单 点能校正. 所得到的能量都经过了零点能校正. 此外,
我们也使用了其它密度泛函，如 B3LYP 和 WB97XD, 在 $6-311++\mathrm{G}(\mathrm{d}, \mathrm{p})$ 理论水平下对 $8-\mathrm{AG}^{\circ+}$ 脱质子反应的 能垒进行计算，结果显示不同水分子模型下, $8-\mathrm{AG}^{-+}$脱 质子反应能垒的变化趋势与使用密度泛函 M06-2X 时一 致(表 S4), 以此来排除不同密度泛函对计算结果的影 响. 所有的计算都是通过 Gaussian 09 程序包进行的 ${ }^{[35]}$.

\section{References}

[1] Seth, P. P.; Tanowitz, M.; Bennett, C. F. J. Clin. Invest. 2019, 129 915.

[2] Zou, X.; Zhao, H.; Yu, Y.; Su, H. J. Am. Chem. Soc. 2013, 135, 4509.

[3] Zou, X.; Dai, X.; Liu, K.; Zhao, H.; Song, D.; Su, H. J. Phys. Chem. B 2014, 118,5864 .

[4] Jie, J.; Xia, Y.; Huang, C.-H.; Zhao, H.; Yang, C.; Liu, K.; Song, D.; Zhu, B.-Z.; Su, H. Nucleic Acids Res. 2019, 47, 11514.

[5] Kim, N.; Choi, J. W.; Song, A. Y.; Choi, W. S.; Park, H. R.; Park, S.; Kim, I.; Kim, H. S. Int. Immunopharmacol. 2019, 67, 152.

[6] Kawada, M.; Amemiya, M.; Sakamoto, S.; Ohishi, T.; Yoshida, J.; Tatsuda, D. Cancer Sci. 2018, 109, 157.

[7] Folkes, L. K.; O'Neill, P. Free Radical Biol. Med. 2013, 58, 14.

[8] de Araujo, A. V. S.; Borin, A. C. J. Phys. Chem. A 2019, 123, 3109.

[9] Zhou, Z. N.; Hu, Z. B.; Zhang, X. W.; Jia, M. H.; Wang, X. L.; Su, H. M.; Sun, H. T.; Chen, J. Q.; Xu, J. H. ChemPhysChem 2019, 20, 757.

[10] Wierzchowski, J.; Medza, G.; Szabelski, M.; StachelskaWierzchowska, A. J. Photochem. Photobiol. A-Chem. 2013, 265, 49.

[11] Kawai, K.; Majima, T. Acc. Chem. Res. 2013, 46, 2616.

[12] Cadet, J.; Wagner, J. R.; Shafirovich, V.; Geacintov, N. E. Int. J. Radiat Biol. 2014, 90, 423.

[13] Wang, Y.; Zhao, H.; Yang, C.; Jie, J.; Dai, X.; Zhou, Q.; Liu, K.; Song, D.; Su, H. J. Am. Chem. Soc. 2019, 141, 1970.

[14] Takada, T.; Kawai, K.; Fujitsuka, M.; Majima, T. Proc. Natl. Acad. Sci. U.S. A. 2004, 101, 14002.

[15] Wu, L. D.; Jie, J. L.; Liu, K. H.; Su, H. M. Acta Chim. Sinica 2014 72,1182 (in Chinese). (吴丽丹, 节家龙, 刘坤辉, 苏红梅, 化学学 报, 2014, 72, 1182.)

[16] Yang, W. Y.; Lei, Z. C.; Hong, W. J.; Huang, F. Z. Acta Chim. Sinica 2019, 77, 951 (in Chinese). (杨威宇, 雷志超, 洪文晶, 黄飞舟, 化 学学报, 2019, 77,951.)

[17] Kobayashi, K.; Tagawa, S. J. Am. Chem. Soc. 2003, 125, 10213.

[18] Wu, L. D.; Liu, K. H.; Jie, J. L.; Song, D.; Su, H. M. J. Am. Chem. Soc. 2015, 137, 259.

[19] Wang, Y.; Zhao, H.; Zhou, Q.; Dai, X.; Liu, K.; Song, D.; Su, H. J. Phys. Chem. B 2019, 123, 2853.

[20] Rokhlenko, Y.; Cadet, J.; Geacintov, N. E.; Shafirovich, V. J. Am. Chem. Soc. 2014, 136, 5956.

[21] Rokhlenko, Y.; Geacintov, N. E.; Shafirovich, V. J. Am. Chem. Soc. 2012, 134, 4955.

[22] Zhang, Q. H.; Wang, Y.; Liu, C.; Yang, Z. Z. Acta Chim. Sinica 2014, 72, 956 (in Chinese). (张千慧, 王阳, 刘翠, 杨忠志, 化学学 报, 2014, 72, 956.)

[23] Lonkar, P.; Dedon, P. C. Int. J. Cancer 2011, 128, 1999.

[24] Wu, Y. J.; Zhai, S. G.; Lu, K.; Gao, L. J. Solid State Electrochem. 2014, $18,1593$.

[25] Li, X.; Cai, Z.; Sevilla, M. D. J. Phys. Chem. B 2001, 105, 10115.

[26] Kumar, A.; Sevilla, M. D. J. Phys. Chem. B 2009, 113, 11359.

[27] Wang, Y. H.; Jie, J. L.; Zhao, H. M.; Bai, Y.; Qin, P. X.; Song, D. Acta Chim. Sinica 2018, 76, 475 (in Chinese). (王英辉，节家龙，赵 红梅, 白羽, 秦佩萱, 宋迪, 化学学报, 2018, 76, 475.)

[28] Zhao, Y.; Truhlar, D. G. Theor. Chem. Acc. 2008, 120, 215.

[29] Wei, S. M.; Wang, Y. H.; Zhao, H. M. Acta Chim. Sinica 2019, 77, 278 (in Chinese). (魏思敏, 王英辉, 赵红梅, 化学学报, 2019, 77, 278.)

[30] Zhao, Y.; Truhlar, D. G. J. Phys. Chem. A 2008, 112, 1095.

[31] Galano, A.; Alvarez-Idaboy, J. R. Phys. Chem. Chem. Phys. 2012, 14, 12476.

[32] Candeias, L. P.; Steenken, S. J. Am. Chem. Soc. 1989, 111, 1094.

[33] Berkelbach, T. C.; Lee, H. S.; Tuckerman, M. E. Phys. Rev. Lett. 2009, 103, 238302

[34] Marx, D.; Tuckerman, M. E.; Hutter, J.; Parrinello, M. Nature 1999, 
$397,601$.

[35] Frisch, M. J.; Trucks, G. W.; Schlegel, H. B.; Scuseria, G. E.; Robb, M. A.; Cheeseman, J. R.; Montgomery, J. A.; Vreven, T.; Kudin, K. N.; Burant, J. C.; Millam, J. M.; Iyengar, S. S.; Tomasi, J.; Barone, V.; Mennucci, B.; Cossi, M.; Scalmani, G.; Rega, N.; Petersson, G. A.; Nakatsuji, H.; Hada, M.; Ehara, M.; Toyota, K.; Fukuda, R.; Ha-segawa, J.; Ishida, M.; Nakajima, T.; Honda, Y.; Kitao, O.; Nakai, H.; Klene, M.; Li, X.; Knox, J. E.; Hratchian, H. P.; Cross, J. B.; Bakken, V.; Adamo, C.; Jaramillo, J.; Gomperts, R.; Stratmann, R. E.; Yazyev, O.; Austin, A. J.; Cammi, R.; Pomelli, C.; Ochterski,
J. W.; Ayala, P. Y.; Morokuma, K.; Voth, G. A.; Salvador, P.; Dannenberg, J. J.; Zakrzewski, V. G.; Dapprich, S.; Daniels, A. D.; Strain, M. C.; Farkas, O.; Malick, D. K.; Rabuck, A. D.; Raghavachari, K.; Foresman, J. B.; Ortiz, J. V.; Cui, Q.; Baboul, A. G.; Clifford, S.; Cioslowski, J.; Stefanov, B. B.; Liu, G.; Liashenko, A.; Piskorz, P.; Komaromi, I.; Martin, R. L.; Fox, D. J.; Keith, T.; Al-Laham, M. A.; Peng, C. Y.; Nanayakkara, A.; Challacombe, M Gill, P. M. W.; Johnson, B.; Chen, W.; Wong, M. W.; Gonzalez, C.; Pople, J. A. Gaussian 09, Revision A. 01, Gaussian, Inc., Wallingford, CT, 2009.

(Cheng, B.) 